\title{
Cyclooxygenase- 2 expression is associated with chemoresistance through cancer stemness property in hypopharyngeal carcinoma
}

\author{
SHIN SAITO ${ }^{1}$, HIROYUKI OZAWA ${ }^{1}$, YORIHISA IMANISHI ${ }^{2}$, MARIKO SEKIMIZU ${ }^{1}$, YOSHIHIRO WATANABE ${ }^{2}$, \\ FUMIHIRO ITO $^{3}$, YUICHI IKARI ${ }^{4}$, NANA NAKAHARA ${ }^{5}$, KAORI KAMEYAMA ${ }^{6}$ and KAORU OGAWA ${ }^{1}$ \\ ${ }^{1}$ Department of Otorhinolaryngology-Head and Neck Surgery, Keio University School of \\ Medicine, Tokyo 160-8582; ${ }^{2}$ Department of Otorhinolaryngology-Head and Neck Surgery, \\ International University of Health and Welfare, Narita, Chiba $286-8582 ;{ }^{3}$ Department of \\ Otorhinolaryngology-Head and Neck Surgery, National Hospital Organization Tokyo Medical Center, \\ Tokyo 152-8902; ${ }^{4}$ Department of Otorhinolaryngology-Head and Neck Surgery, Kawasaki Municipal Kawasaki Hospital, \\ Kawasaki, Kanagawa 210-0013; ${ }^{5}$ Department of Otorhinolaryngology-Head and Neck Surgery, Saitama City Hospital, \\ Saitama 336-8522; ${ }^{6}$ Department of Pathology, Keio University School of Medicine, Tokyo 160-8582, Japan
}

Received January 15, 2021; Accepted April 20, 2021

DOI: $10.3892 / \mathrm{ol} .2021 .12794$

\begin{abstract}
Cyclooxygenase-2 (COX-2) is one of the two isoforms of COX, an enzyme that catalyzes the conversion of arachidonic acid to prostaglandins. COX-2 is associated with the progression in various types of cancer, and its expression has been associated with a poor prognosis in head and neck squamous cell carcinoma (HNSCC). Furthermore, COX-2 expression has been associated with resistance to anticancer drugs. However, the precise mechanism of COX-2 for chemoresistance in HNSCC has not been fully elucidated. The present study aimed to investigate the effect of COX-2 on cancer stem cell (CSC) property and to reveal its effect on chemoresistance using in vitro and clinicopathological assays in HNSCC cells and tissues. The current study analyzed the immunohistochemical expression levels of COX-2 and clinicopathological factors using matched samples of pretreatment biopsy and surgical specimens from patients with hypopharyngeal carcinoma who underwent tumor resection with preoperative chemotherapy, including docetaxel. Additionally, the chemoresistance to docetaxel with or without a COX-2 inhibitor (celecoxib) was examined in HNSCC cell lines by MTS assays. To evaluate the association of COX-2 expression with stemness property, the expression levels of CSC-associated genes after exposure to celecoxib were
\end{abstract}

Correspondence to: Dr Shin Saito, Department of Otorhinolaryngology-Head and Neck Surgery, Keio University School of Medicine, 35 Shinanomachi, Shinjuku, Tokyo 160-8582, Japan

E-mail: saitoshin3@gmail.com

Key words: cyclooxygenase-2, cancer stemness, chemoresistance, hypopharyngeal carcinoma, head and neck cancer, prostaglandin E receptor 2 assessed by reverse transcription-quantitative PCR. A sphere formation assay was also performed using ultra-low attachment dishes and microscopic imaging. The immunohistochemical analysis of biopsy specimens revealed a negative association between COX-2 expression in biopsy specimens and the pathological effect of induction chemotherapy in surgical specimens. The cell survival rate under exposure to docetaxel was decreased by the addition of celecoxib. COX-2 inhibition led to downregulation of CSC-associated gene expression and sphere formation. The present findings suggested that COX-2 expression may be associated with chemoresistance through the cancer stemness property, and inhibition of COX-2 may enhance chemo-sensitivity in HNSCC. Therefore, COX-2 may be an attractive target for the treatment of HNSCC.

\section{Introduction}

Head and neck squamous cell carcinoma (HNSCC) is the sixth leading cancer by incidence worldwide (1). Treatment modalities for HNSCC have advanced, but there is still a high incidence of recurrence after initial therapy with rates of 40-50\% reported for hypopharyngeal carcinoma $(2,3)$. The cancer stem cell hypothesis $(4,5)$ allows us to explain the heterogeneity and resistance to anticancer treatment of a malignant tumor, including head and neck cancers. Numerous studies about the detection and control of this cell have been reported, but there are no clinically approved treatments to date (6).

Cyclooxygenase (COX) is an enzyme catalyzing the conversion of arachidonic acid to prostaglandins (PGs). COX-1 is constitutively expressed in various tissues throughout the body, whereas COX-2 expression is induced in sites of inflammation, including cancer and premalignant lesions. COX-2 expression is elevated in HNSCCs (7-9), and seems to have a negative correlation with survival (10-13). This is explained by multiple reasons, including promotion in tumor progression (12), proliferation (14), angiogenesis (10), and 
lymph node metastasis (15). We have previously reported that COX-2 expression is related to lymph node metastasis in oropharyngeal carcinomas (16) and that COX-2 inhibition can have an anti-metastatic effect through the suppression of epithelial to mesenchymal transition (EMT) in pharyngeal carcinoma (17). Furthermore, of the four downstream receptors of PG E2 (PGE2), which are EP1-4, we have recently reported that $\mathrm{PG} \mathrm{E}$ receptor $2(\mathrm{EP} 2)$ plays an efficient role in EMT in hypopharyngeal carcinoma (18). COX-2 expression is also related to resistance to anticancer therapies, such as chemotherapy $(13,19-21)$ and radiotherapy $(22)$ in other cancer sites. Recently, the interaction of the COX2/PGE2/EP axis and cancer stemness (23-26) has been reported, but little has been studied in HNSCCs. Moreover, no studies have reported the association of COX-2 expression and cancer stemness, especially chemo-sensitivity in HNSCCs.

Here, we aimed to investigate the effect of COX-2 on cancer stem cell (CSC) property and to reveal its effect on chemo-resistance by in vitro and clinicopathological assays in HNSCCs.

\section{Materials and methods}

Cell lines. Human pharyngeal carcinoma cell lines (FaDu and Detroit 562) were purchased from American Type Culture Collection (ATCC).

Cell culture. Cell lines were cultured in Eagle's Minimum Essential Medium (Sigma-Aldrich; Merck KGaA) supplemented with $10 \%$ fetal bovine serum (FBS, US origin) and $1 \%$ penicillin-streptomycin (solution stabilized, Sigma-Aldrich; Merck $\mathrm{KGaA})$, and incubated in a humidified incubator $\left(37^{\circ} \mathrm{C}\right.$, $5 \%$ carbon dioxide). Cells were subcultured continuously according to the ATCC protocol.

Drugs and reagents. The selective COX-2 inhibitor (celecoxib), selective EP2 antagonist (PF-04418948), and docetaxel (DTX) were purchased from Toronto Research Chemicals, Cayman Chemical, and Sigma-Aldrich (Merck KGaA), respectively. Dimethyl sulfoxide (DMSO) was used as a solvent and vehicle control.

Reverse transcription-quantitative PCR. The RNeasy mini kit (Qiagen) was used for RNA extraction, and the SuperScript $^{\mathrm{TM}}$ III First-Strand Synthesis System (Invitrogen; Thermo Fisher Scientific, Inc.) for complementary DNA synthesis. Quantitative real-time polymerase chain reaction (PCR) was performed using the 7500 Fast Real-Time PCR system instrument and software (Applied Biosystems; Thermo Fisher Scientific, Inc.) following the manufacturer's protocol. Primers and probes were purchased from Applied Biosystems (TaqMan ${ }^{\circledR}$ Gene Expression Assays) with the following IDs: $\beta$-actin (actin beta, Hs01060665_g1), OCT3/4 (POU class 5 homeobox 1, Hs04260367_gH), NANOG (nanog homeobox, Hs04399610_g1), SOX-2 (SRY-box 2, Hs01053049_s1), ALDH1A1 (aldehyde dehydrogenase 1 family member A1, Hs00946916_m1), CD44 (CD44 molecule, Hs01075861_m1), COX-2 (prostaglandin-endoperoxide synthase 2, Hs00153133_m1), EP1 (prostaglandin E receptor 1, Hs00168752_m1), EP2 (prostaglandin E receptor 2, Hs00168754_m1), EP3 (prostaglandin E receptor 3, Hs00168755_m1), and EP4 (prostaglandin E receptor 4, Hs00168761_m1). The PCR amplification conditions were as follows: $20 \mathrm{sec}$ at $95^{\circ} \mathrm{C}$ followed by 40 cycles of 3 -sec denaturation at $95^{\circ} \mathrm{C}$ and $30 \mathrm{sec}$ annealing at $60^{\circ} \mathrm{C}$. We quantified the relative gene expression levels using the standard curve method, and compared the levels to $\beta$-actin, which was used as an endogenous control.

COX-2 inhibition and EP2 inhibition for messenger RNA extraction. Cells were seeded at a density of $200 / \mu 1$ into a six-well dish and incubated in a medium containing $10 \%$ FBS. Twenty-four hours later, the cells were treated with celecoxib (5 $\mu \mathrm{M})$ or PF-04418948 $(10 \mu \mathrm{M})$. These concentrations of the reagents were found to be optimal with no toxic effect on cell viability up to at least $48 \mathrm{~h}$ in our preliminary experiments. Treatment with DMSO was used as controls. Cells were collected $12 \mathrm{~h}$ later and used for total RNA extraction. The experiment in each condition was performed at least three times to assess consistency.

COX-2 knockdown. Cells were seeded at a density of 10,000/ml into a six-well dish in a serum-reduced medium (Opti-MEM, Thermo Fisher Scientific, Inc.). Twenty-four hours later, the medium was changed and siRNA for the COX-2 gene PTGS2 (Silencer ${ }^{\circledR}$ Pre-designed siRNA, Life Technologies) and negative control siRNA (Silencer ${ }^{\circledR}$ Select Negative Control siRNA, Life Technologies) were added at a density of 20 pmol with lipofectamine (Thermo Fisher Scientific, Inc.). Twenty-four hours later, the cells were scraped and collected for analysis.

Cell proliferation assay. Cells were seeded to a 96-well dish at a density of 1,000 cells/200 $\mu \mathrm{l} /$ well, and incubated in a medium containing $10 \%$ FBS overnight. The medium was changed the next day and treated with the following drugs: i) multiple density of DTX between $0.005 \mathrm{nM}$ and $50 \mu \mathrm{M}+\mathrm{DMSO}$; ii) multiple density of DTX between $0.005 \mathrm{nM}$ and $50 \mu \mathrm{M}+$ celecoxib $(5 \mu \mathrm{M})$; and iii) multiple density of DTX between $0.005 \mathrm{nM}$ and $50 \mu \mathrm{M}+\mathrm{PF}-04418948(10 \mu \mathrm{M})$. Cell viability was checked $72 \mathrm{~h}$ later with the CellTiter $96^{\circledR}$ AQueous One Solution Cell Proliferation Assay (Promega), as per the manufacturer's instruction. Briefly, $20 \mu \mathrm{l}$ of the reagent containing the tetrazolium compound and phenazine ethosulfate were added to each well, and the plate was incubated for $4 \mathrm{~h}$ at $37^{\circ} \mathrm{C}$. Viable cells were quantified by measuring the optical density values of absorbance at $490 \mathrm{~nm}$ using a microplate reader. The experiment was performed three times and run in triplicate each time.

Immunofluorescence staining. For immunofluorescence staining of Ki-67, FaDu and Detroit 562 cells were seeded in slide chambers (Thermo Fisher Scientific, Inc.) and treated with DMSO alone, $10 \mu \mathrm{M}$ of celecoxib, $50 \mathrm{nM}$ of DTx, and $10 \mu \mathrm{M}$ of celecoxib $+50 \mathrm{nM}$ of DTX for $24 \mathrm{~h}$. After washing the cells extensively with phosphate-buffered saline (PBS), the cells were fixed with $4 \%$ paraformaldehyde fixative for 15 min. After washing with PBS, the cells were incubated with anti-Ki-67 mouse antibody (ab245113, Abcam) at 1:100 overnight. Goat anti-Mouse IgG Alexa Fluor (Thermo Fisher Scientific, Inc.) was used for secondary antibody, and Hoechst 
A

Grading of pathological effect of neoadjuvant chemotherapy

\begin{tabular}{|cl|}
\hline grade & \multicolumn{1}{c|}{ definition } \\
\hline 1 & $\begin{array}{l}\text { Almost no observable treatment-induced tumor } \\
\text { degeneration or necrosis. }\end{array}$ \\
2 & $\begin{array}{l}\text { Degeneration or necrosis in }-2 / 3 \text { cancer cells. } \\
\text { disappearance of over } 2 / 3 \text { of cancer cells. }\end{array}$ \\
3 & $\begin{array}{l}\text { Entire tumor is necrotic or liquefied, disappeared, } \\
\text { or replaced by granulation tissue or fibrosis. }\end{array}$ \\
\hline
\end{tabular}

B

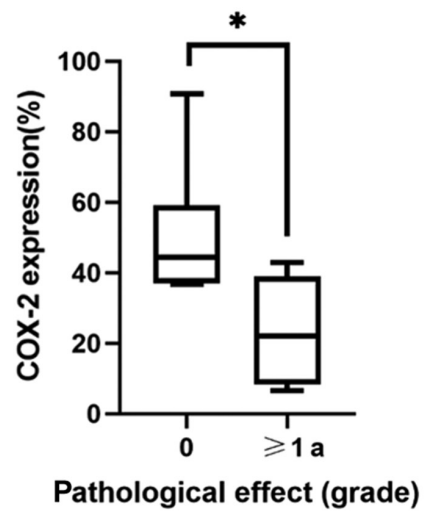

Figure 1. Pathological effect after induction chemotherapy. (A) Definition of grading of the pathological effect of induction chemotherapy. (B) Association of COX-2 expression of pretreatment biopsy specimens and the pathological effect of induction chemotherapy. Tumors with a high pretreatment COX-2 expression tended to be resistant to induction chemotherapy. ${ }^{*} \mathrm{P}<0.05$. COX-2, cyclooxygenase- 2 .

33258 was used for nuclear staining. Ki-67 positive cells were counted from four randomly chosen areas at 10x magnification.

Sphere formation assay. Cells were seeded with a serum-free medium into an ultra-low attachment dish (Corning) at a density of 500 cells $/ \mathrm{ml}$. The medium was supplemented with $20 \mathrm{ng} / \mathrm{ml}$ of the human basic fibroblast growth factor (Sigma-Aldrich, catalog no. F0291) and $20 \mathrm{ng} / \mathrm{ml}$ of the human epidermal growth factor (Sigma-Aldrich, catalog no. E5036). Celecoxib was added at two different densities; 1 and $10 \mathrm{nM}$, and DMSO was used for control. Cells were cultured for 7 days, and the number of spheres per well was counted manually on day 7 .

Patients and tissue specimens. In order to assess the pathological effect of chemotherapy, patients who were diagnosed as hypopharyngeal carcinoma after biopsy and received surgical resection of the tumor after induction chemotherapy at Keio University Hospital between April 1, 2010 and March 31, 2015 were analyzed. Tissue samples from the hospital tissue bank and their medical records were obtained retrospectively. The protocols for the use of the clinical materials were approved by the Institutional Ethics Review Board of the Ethics Committee of Keio University School of Medicine (reference nos. 2010-013 and 2010-013-2). Informed consent was obtained in the form of opt-out on the web-site and by information in the hospital. All procedures for clinical tissues were performed in accordance with the principles of the 1964 Helsinki Declaration and its later amendments.

Pathological judgement was used because it is difficult to accurately measure the size of hypopharyngeal lesions under radiographic evaluations and pathological assessment is more direct. Pretreatment biopsy specimens and surgically resected tumor specimens from 12 pathologically diagnosed hypopharyngeal carcinoma patients who received induction chemotherapy (DTX $60 \mathrm{mg} / \mathrm{m}^{2}$, cisplatin $60 \mathrm{mg} / \mathrm{m}^{2}$, fluorouracil $700 \mathrm{mg} / \mathrm{m}^{2}$ ) after biopsy were analyzed. All patients had no history of other head and neck carcinoma and had not received prior treatment, including chemotherapy and radiotherapy. All specimens were fixed with $10 \%$ formalin, embedded with paraffin, and sliced at $5 \mu \mathrm{m}$ each. The pathological effect of induction chemotherapy was evaluated by one trained head and neck pathologist, who was blinded to the data concerning COX-2 expression. The effects were graded according to the following grading system: Grade 0 , no effect; grade 1, slight effect; grade 2, moderate effect; and grade 3, significant effect (Fig. 1A) (19). Univariate analyses of the pathological effect of chemotherapy and age, the $\mathrm{T}$ stage, $\mathrm{N}$ stage, clinical stage, and COX-2 expression were performed.

Immunohistochemistry. Immunostainings were performed with the automated immunostaining machine Ventana Discovery XT (Roche Diagnostics/Ventana Medical Systems), as per the manufacturer's instructions and using the ultraView Universal DAB Detection Kit (Roche/Ventana). The COX-2 primary antibody (catalog number $760-4254$, product code 518101862) was purchased from Roche Diagnostics K.K. The ratio of COX-2 positive tumor cells was calculated by using the computational software Tissue Studio ${ }^{\circledR}$ (Definiens, Inc.). For each slide, the region of interest (ROI) was set for the whole tumor or for biopsy specimens for the tumorous area. A hematoxylin threshold of 0.1 , typical nucleus size of $60 \mu \mathrm{m}^{2}$, maximum cell growth of 10 , and classification of 0.1 were set, and the expression of COX-2 was automatically calculated by the number of COX-2-positive tumor cells divided by the number of total tumor cells.

Statistical analysis. The data repeatedly obtained in the in vitro assays are presented as the mean \pm standard deviation of three or more independent experiments. GraphPad Prism 8.3.0 (GraphPad Software, Inc.) was used to perform the statistical analysis. Fisher's exact test was used to analyze the association between patient clinicopathological characteristics and COX-2 expression. The difference in COX-2 expression by pathological response was analyzed using the Wilcoxon rank-sum test. Results of the cell proliferation assay were analyzed using non-linear regression analysis. Student's t-test was used for mRNA expression 
Table I. Clinicopathological characteristics of 12 patients with hypopharyngeal carcinoma.

\begin{tabular}{lc}
\hline Characteristics & Value \\
\hline Sex, male/female, $\mathrm{n}$ & $12 / 0$ \\
Mean age (range), years & $63(49-80)$ \\
Subsite, $\mathrm{n}$ & \\
Piriform sinus & 11 \\
Posterior wall & 1 \\
Post-cricoid & 0 \\
T stage $1 / 2 / 3 / 4, \mathrm{n}$ & $2 / 7 / 2 / 1$ \\
N stage $0 / 1 / 2 / 3, \mathrm{n}$ & $4 / 2 / 5 / 1$ \\
Stage I/II/III/IV, n & $1 / 2 / 3 / 6$ \\
\hline
\end{tabular}

comparison. Sphere formation assay was analyzed using one-way ANOVA followed by Dunnett's multiple comparison test. $\mathrm{P}<0.05$ was considered to indicate a statistically significant difference.

\section{Results}

COX-2 expression is significantly associated with the pathological effect of induction chemotherapy. Pretreatment biopsy specimens and surgical specimens after induction chemotherapy were obtained from 12 patients with hypopharyngeal carcinoma. Patients' characteristics are summarized in Table I. The COX-2 expression varied from 6.6 to $91 \%$, with a mean of $36 \%$. In this study, in order to classify COX-2 expression, we used this mean as a cutoff, and divided the group into two; above mean, and below mean. COX-2 expression was classified into two groups, as its positive cutoff rate was $35 \%$. There was a negative correlation between COX-2 expression and the pathological effect of induction chemotherapy (Table II and Fig. 1B), showing that tumors with high pretreatment COX-2 expression tended to be resistant to induction chemotherapy. According to univariate analysis, the relationship between the pathological effect of chemotherapy and COX-2 expression was statistically significant $(\mathrm{P}=0.015)$ (Table II). Median pretreatment $\mathrm{COX}-2$ expression in patients with no pathological response to chemotherapy was $44 \%$, and that in patients who showed a response was $22 \%$; this difference was statistically significant $(\mathrm{P}=0.03)$. Representative cases are shown in Fig. 2.

COX-2 inhibitor improves chemo-sensitivity to docetaxel in head and neck squamous cell carcinoma cell lines. The result of the cell viability assay with the addition of celecoxib to multiple densities of DTX is shown in Fig. 3. The $\mathrm{IC}_{50}$ decreased significantly with the addition of celecoxib in $\mathrm{FaDu}\left(\log \mathrm{IC}_{50}\right.$ DTX versus [vs.] DTX+celecoxib: -8.542 vs. 09.111; 95\% CI of $\log \mathrm{IC}_{50}$ DTX vs. DTX+celecoxib: -8.804 to -8.291 vs. -9.480 to -8.817$)$. The addition of celecoxib also decreased the $\mathrm{IC}_{50}$ of Detroit 562, but this was not statistically significant $\left(\log \mathrm{IC}_{50}\right.$ DTX and DTX+celecoxib: -8.644 and -8.881 , respectively; 95\% CI of $\operatorname{LogIC}_{50}$ DTX and DTX+celecoxib: -9.077 to -8.448 and -9.309 to -8.847 , respectively) (Fig. 3A and $\mathrm{B}$ ).
Table II. Association between pathological effect of chemotherapy and clinicopathological characteristics.

\begin{tabular}{|c|c|c|c|}
\hline \multirow[b]{2}{*}{ Characteristic } & \multicolumn{2}{|c|}{ Pathological effect } & \multirow[b]{2}{*}{ P-value } \\
\hline & 0 & $\geq 1 \mathrm{a}$ & \\
\hline Age, years & & & 0.54 \\
\hline$\leq 65$ & 3 & 5 & \\
\hline$>65$ & 3 & 1 & \\
\hline T stage & & & 0.18 \\
\hline $1+2$ & 6 & 3 & \\
\hline $3+4$ & 0 & 3 & \\
\hline N stage & & & 0.08 \\
\hline $0+1$ & 5 & 1 & \\
\hline $2+3$ & 1 & 5 & \\
\hline Stage & & & 0.18 \\
\hline $1+2$ & 3 & 0 & \\
\hline $3+4$ & 3 & 6 & \\
\hline COX-2 expression, $\%$ & & & $0.015^{\mathrm{a}}$ \\
\hline$\leq 36$ & 0 & 5 & \\
\hline$>36$ & 6 & 1 & \\
\hline
\end{tabular}

${ }^{\mathrm{a}} \mathrm{P}<0.05$ by Fisher's exact test.

EP2 inhibitor tends to improve chemo-sensitivity to docetaxel in head and neck squamous cell carcinoma cell lines. The addition of the selective EP2 antagonist (PF-04418948) tended to improve chemo-sensitivity; however, it was not statistically significant in $\mathrm{FaDu}\left(\mathrm{LogIC}_{50}\right.$ DTX and DTX+PF-04418948: -7.793 and -8.422 , respectively; $95 \% \mathrm{CI}$ of $\mathrm{LogIC}_{50} \mathrm{DTX}$ and DTX+PF-04418948: -8.475 to -6.925 and -9.017 to -7.772, respectively) nor Detroit 562 ( $\operatorname{LogIC}_{50}$ DTX and DTX+PF-04418948: -8.320 and -8.470 , respectively; $95 \% \mathrm{CI}$ of $\operatorname{LogIC}_{50}$ DTX and DTX+PF-04418948: -8.688 to -7.959 and -8.829 to -8.098 , respectively) (Fig. 3C and D).

COX-2 inhibitor suppresses Ki-67 expression in head and neck squamous cell carcinoma cell lines. From immunofluorescence staining, Ki-67 expression significantly decreased in Detroit 562 after celecoxib treatment and combined treatment of DTX and celecoxib. In FaDu, celecoxib alone did not show significant difference, whereas combination treatment showed significant suppression of Ki-67 expression. (Fig. 4)

Baseline messenger RNA expression of prostaglandin E2 receptor genes vary between cell lines. Baseline messenger RNA (mRNA) expression of PGE2 receptors is shown in Fig. 5. Expression of EP1 was not detected in either cell lines. Relative quantification of PGE2 receptors against $\beta$-actin varied between the two cell lines. Detroit 562 showed a higher degree of expression in all receptor genes compared to FaDu, significantly in EP3 and EP4.

COX-2 inhibitors reduce messenger RNA expression of stemness-related genes. COX-2 inhibition by celecoxib led to downregulation of expressions in OCT3/4, NANOG, and 


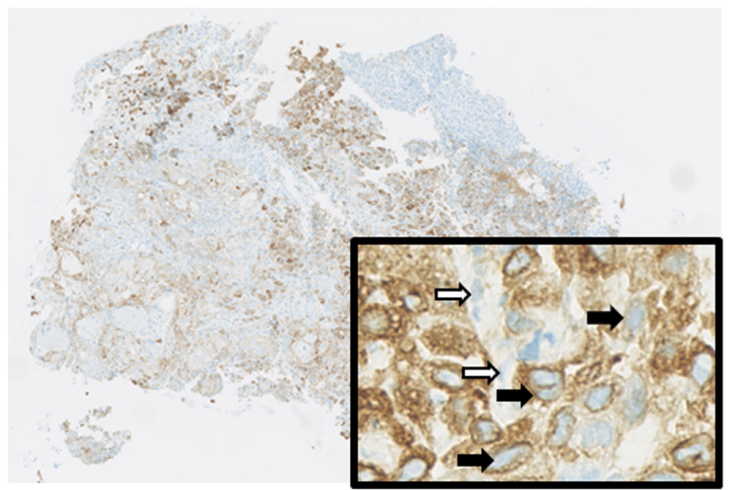

$91.9 \%$, Grade 0

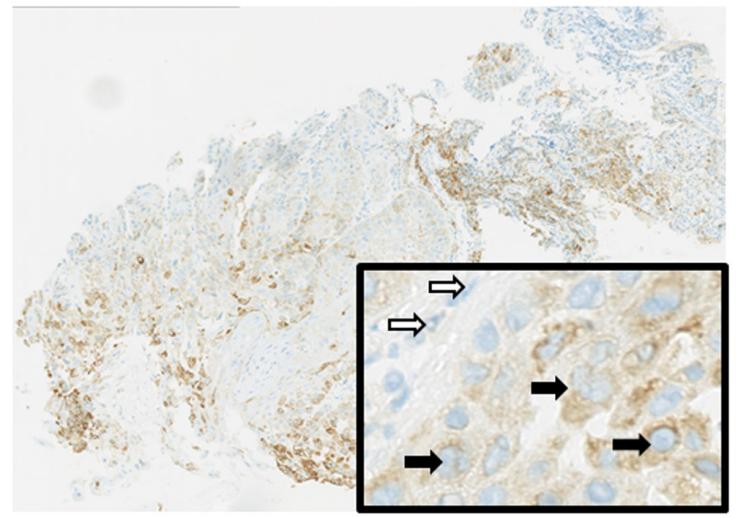

$90.8 \%$, Grade 0

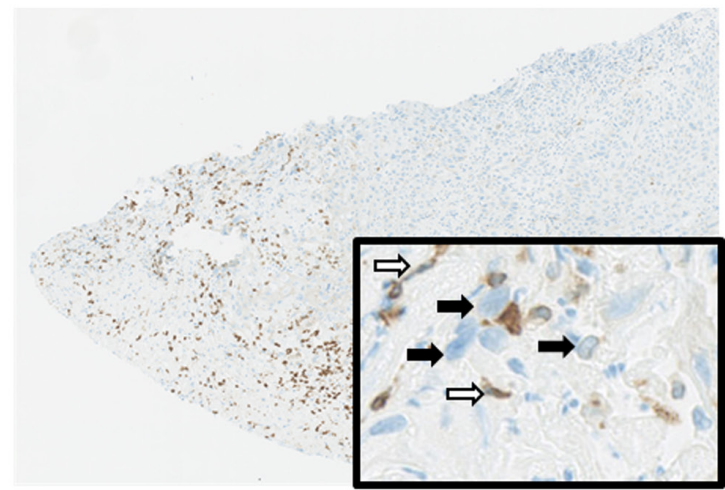

$10.7 \%$, Grade 2

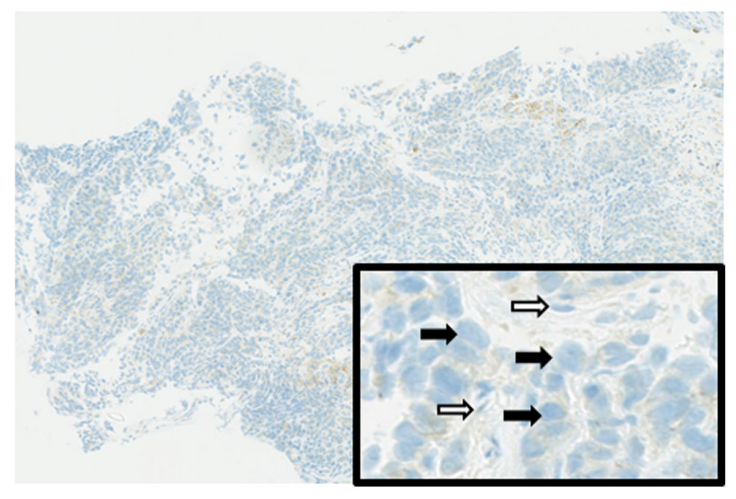

$6.6 \%$, Grade 1

Figure 2. Immunohistological staining of COX-2 in pretreatment biopsy specimens. Percentage and grade represent the percentage of COX-2-positive cells and the grade of pathological effect. Original magnification, x10. Figure in black box shows magnification of x80. Black arrows indicate tumor cells, while white arrows indicate stromal cells. COX-2, cyclooxygenase-2.
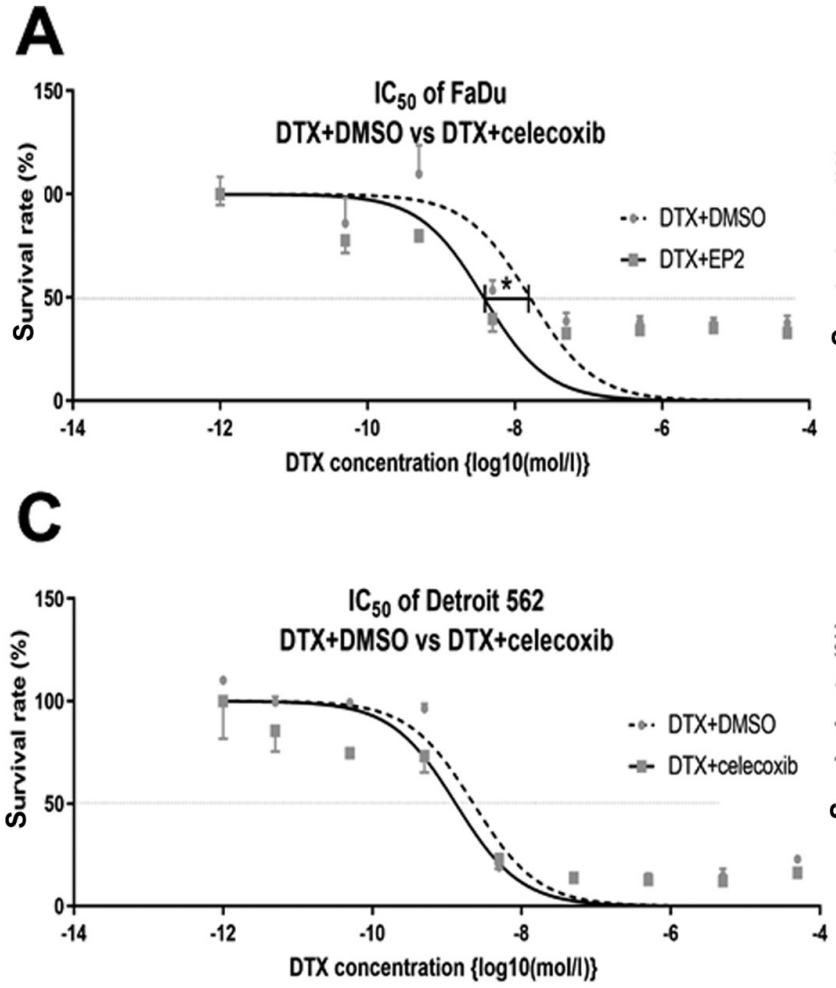

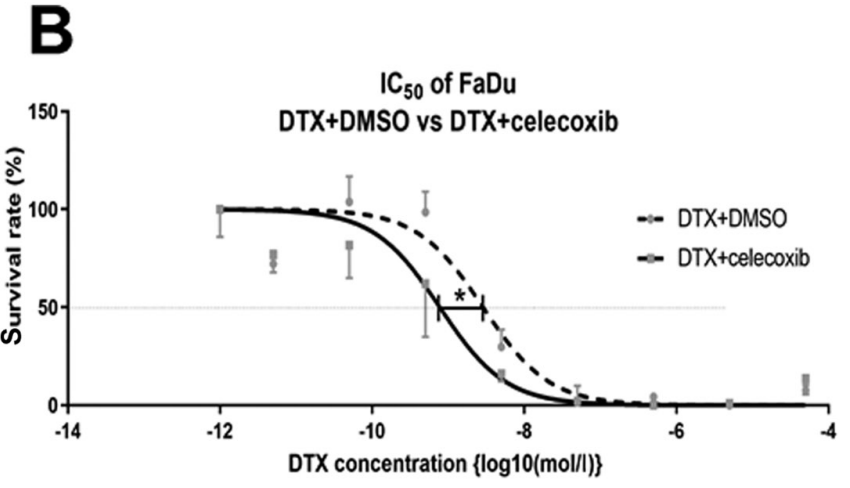

D

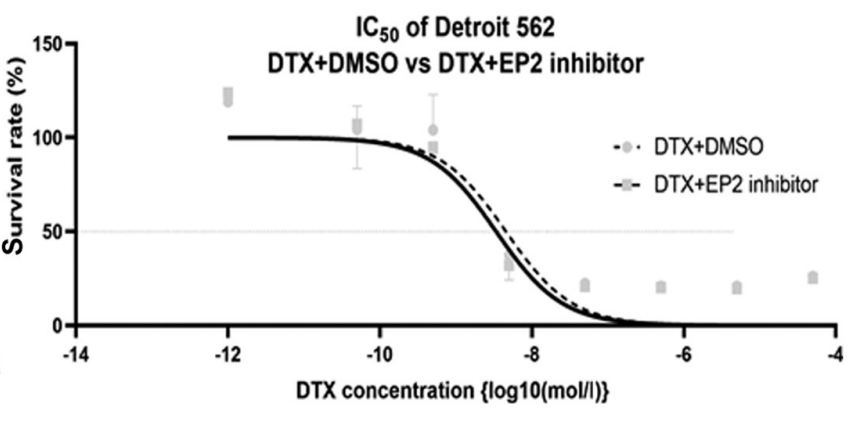

Figure 3. Cell survival rate curves of hypopharyngeal carcinoma cells. DTX concentration is shown as $\log 10(\mathrm{~mol} / \mathrm{l})$. FaDu cells treated with (A) DTX $+5 \mu \mathrm{M}$ celecoxib or (B) DTX + EP2 inhibitor. Detroit 562 cells treated with (C) DTX $+5 \mu \mathrm{M}$ celecoxib or (D) DTX + EP2 inhibitor. IC $\mathrm{C}_{50}$ decreased significantly by addition of celecoxib in FaDu cells, but not in Detroit 562 cells. "P<0.05. DTX, docetaxel; EP2, prostaglandin E receptor 2. 


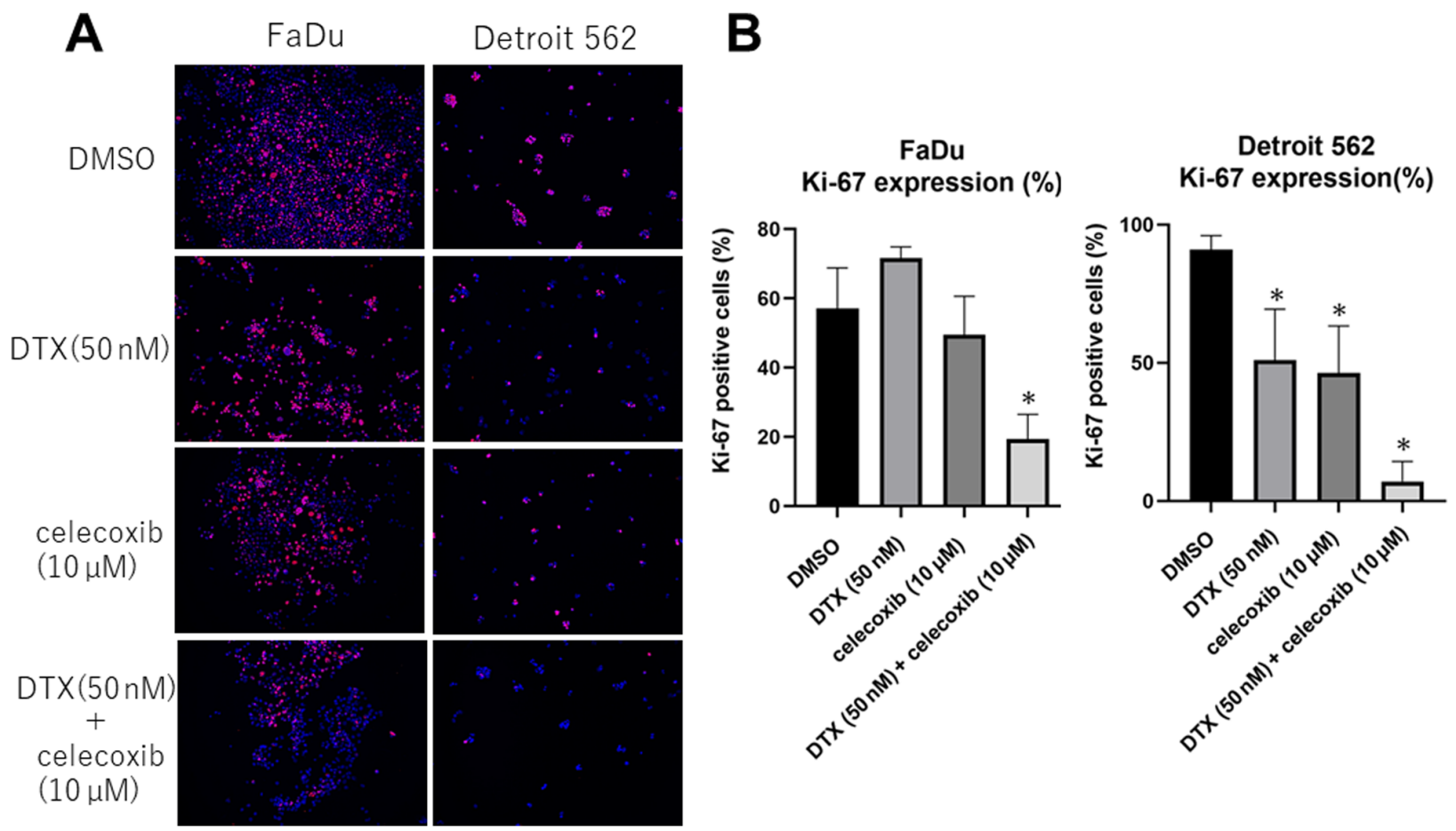

Figure 4. Immunofluorescence staining of Ki-67. (A) Representative images of Ki-67 expression (pink) merged with Hoechst staining (blue). Original magnification, $\mathrm{x} 10$. (B) Percentage of Ki-67-positive cells. " $\mathrm{P}<0.05$ vs. DMSO. DTX, docetaxel.

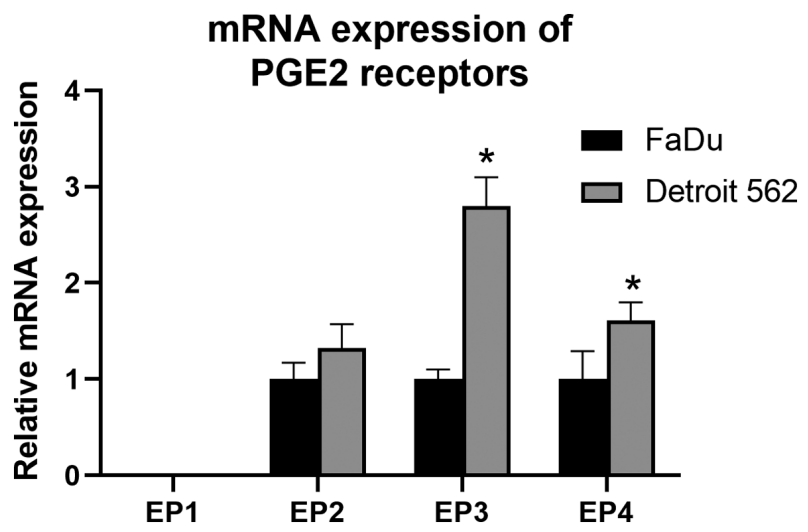

Figure 5. Baseline mRNA expression levels of PGE2 receptors EP1-4 in $\mathrm{FaDu}$ and Detroit 562 cells. Expression levels varied between the two cell lines. ${ }^{*} \mathrm{P}<0.05$ vs. FaDu cells. PG, prostaglandin; EP1-4, PG E receptor 1-4.

SOX-2 in both cell lines (Fig. 6A and B). There was no significant change in ALDH1A1 expression throughout the inhibition assay. COX-2 knockdown cells also showed a similar alteration compared to celecoxib treatment, decreasing the expressions of OCT3/4, NANOG, and SOX-2 (Fig. 6C and D). PTGS2 was significantly decreased in both cell lines compared to negative control, confirming that transfection successfully knocked down COX-2. EP2 inhibition showed a similar but slightly different alteration, decreasing the expressions of OCT3/4, NANOG, SOX-2 and ALDH1A1 in both cell lines, and CD44 in Detroit 562 (Fig. 6E and F).

COX-2 inhibitors suppress sphere formation in head and neck squamous cell carcinoma cell lines. Cells cultured with celecoxib established smaller spheres, whereas cells cultured in DMSO developed larger spheres in both cell lines (Fig. 7A and B). Celecoxib of 1 and $10 \mathrm{nM}$ showed a significant suppression in the number of spheres established compared with DMSO (Fig. 7C), and this effect was observed in a concentration dependent manner. EP2 inhibitors did not show any positive effect (data not shown).

\section{Discussion}

From our clinicopathological assays, patients with hypopharyngeal carcinoma who had high COX-2 expression showed tolerance to the following induction chemotherapy, indicating that COX-2 expression is related to chemotherapeutic resistance. Similar studies using pretreatment biopsy specimens to predict chemo-sensitivity have been reported in esophageal carcinoma (27) and nasopharyngeal carcinoma (19), but there are no reports of hypopharyngeal squamous cell carcinomas. Our result was compatible with findings of these previous reports showing that tumors with high COX-2 expression pretreatment were resistant to the following chemotherapy.

Furthermore, we found that COX-2 inhibition improves chemo-sensitivity in HNSCCs in vitro. Using pharyngeal carcinoma cell lines, the chemo-sensitivity to DTX improved with the addition of celecoxib. Immunofluorescence analysis revealed that combination treatment of DTX and celecoxib suppresses Ki-67 in a significant manner. Celecoxib itself showed effect on Ki-67 expression in Detroit 562, but considering the low dose of celecoxib we used and the fact that addition of celecoxib to DTX significantly decreased Ki-67 in both cell lines regardless of the effect of single celecoxib treatment, celecoxib seems to have anti-cancer effects other than proliferation suppression. Previous studies have shown 
A
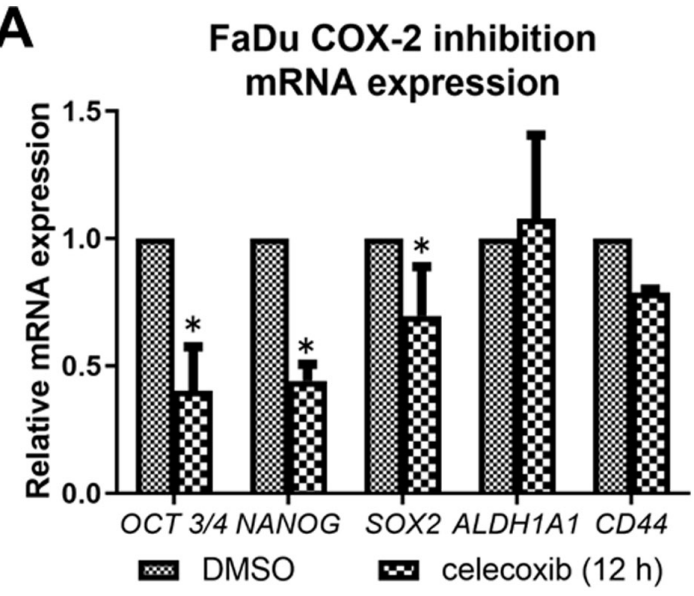

C

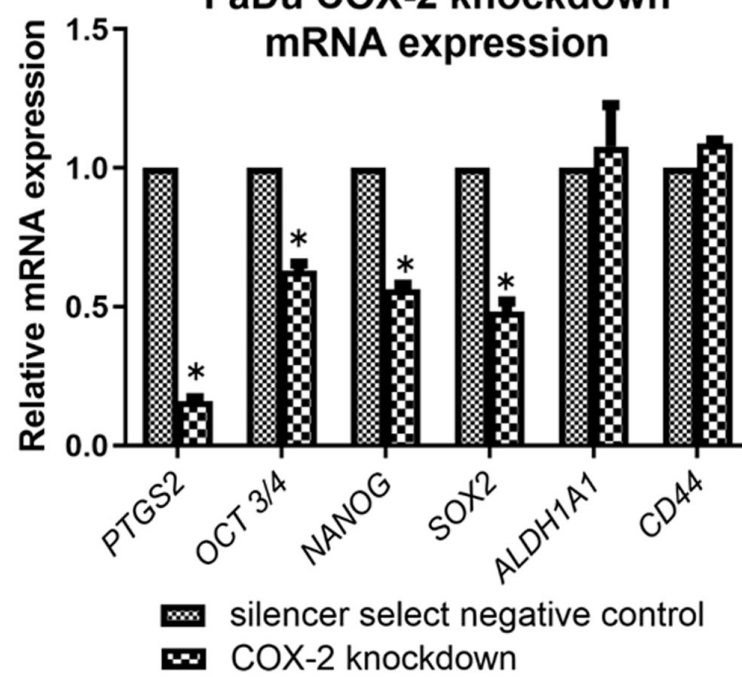

E

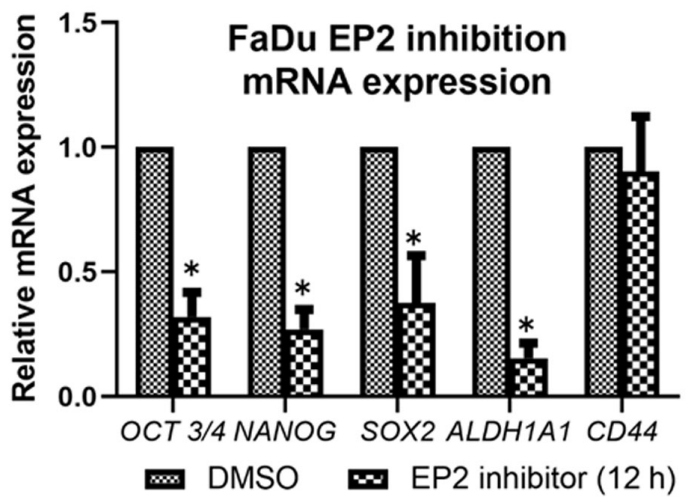

B
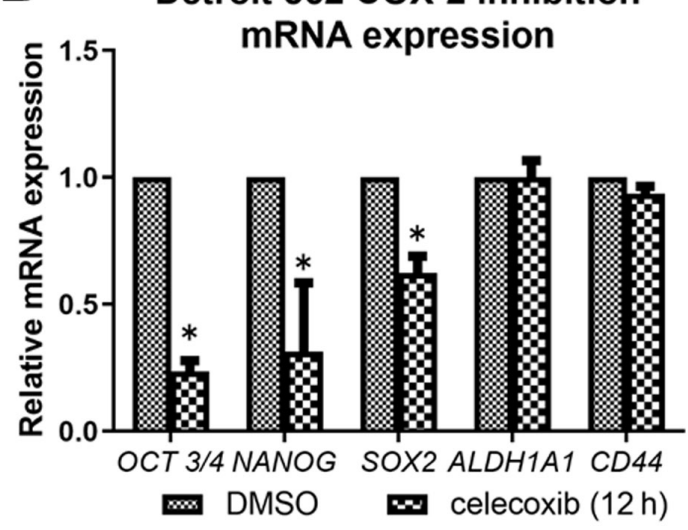

D
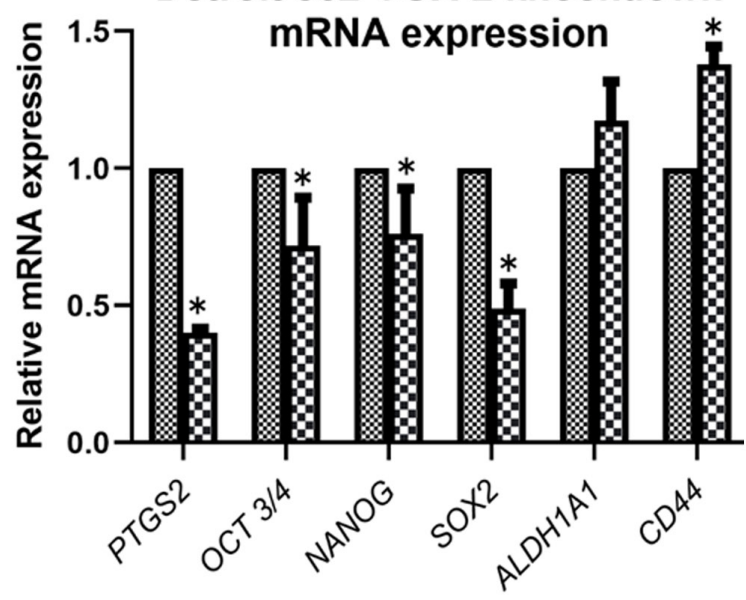

silencer select negative control

COX-2 knockdown

$\mathbf{F}$

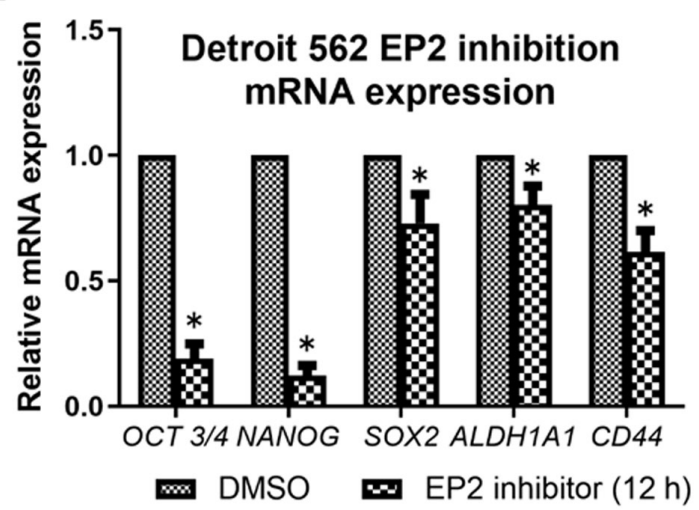

Figure 6. Alterations in the mRNA expression levels of stem cell-associated genes in FaDu and Detroit 562 cells. Cells were treated by (A and B) celecoxib, (C and D) COX-2-knockdown and (E and F) EP2 inhibitor. "P<0.05 vs. DMSO or negative control. COX-2, cyclooxygenase-2; EP2, prostaglandin E receptor 2; OCT3/4, POU class 5 homeobox 1; NANOG, nanog homeobox; SOX-2, SRY-box 2; ALDH1A1, aldehyde dehydrogenase 1 family member A1.

that celecoxib enhances anti-tumor activity by promoting apoptosis (28-30) and inhibiting DNA repair (22,31). Besides these pathways, controlling cancer stemness can also be one reason for improvement of chemo-resistance (32-34).

COX-2 and its metabolic product PGE2 play an important role in maintaining cancer stemness and activating repopulation (35). In this study, celecoxib downregulated cancer stem cell-related genes such as OCT3/4, NANOG, and SOX-2 in pharyngeal carcinoma cell lines, and led to the inhibition of sphere formation, one of the characteristics of cancer stem cells. Similarly, knockdown of PTGS2 led to downregulation of OCT3/4, NANOG, and SOX-2. Previous reports also demonstrated that COX-2 was co-expressed with CSC markers including SOX-2, OCT3/4, and ALDH (36), and upregulation of COX-2 was associated with increased chemo-resistance in CSC-like side population cells (37). The mechanism regulating 


\section{Sphere formation assay}

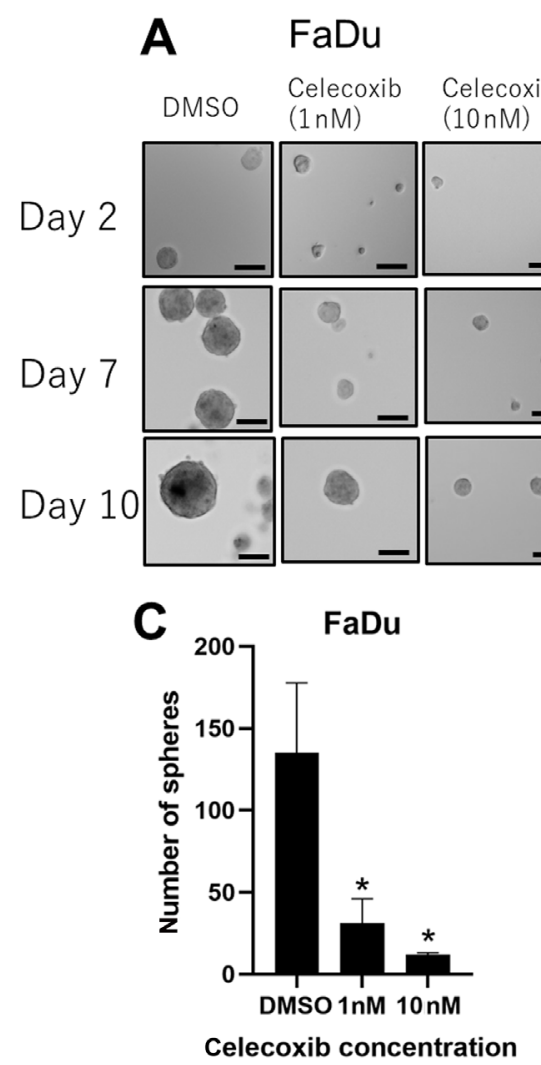

B Detroit 562
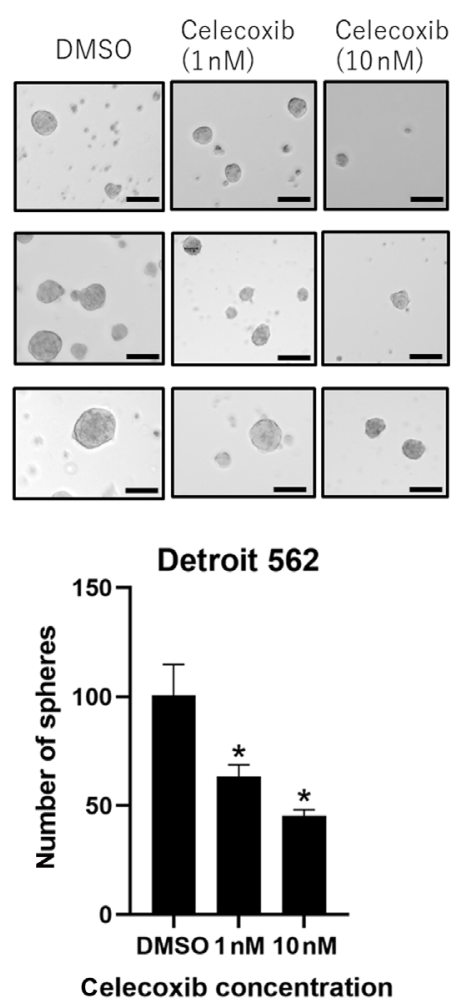

Figure 7. Sphere formation assays. Microscopic images of sphere formation assay in (A) FaDU and (B) Detroit 562 cells (scale bar, $100 \mu \mathrm{m}$ ). (C) Number of spheres counted manually. ${ }^{\text {P }}<0.05$ vs. DMSO.

cancer stemness by COX-2 has not been fully elucidated, but interaction between the COX2/PGE2/EP axis and cancer stemness by signaling molecules, such as Wnt (23-25) and STAT3 (26), are assumed to control this effect. All of these documented data suggest that COX-2 expression is related to CSC, and can play a role in chemo-resistance. Therefore, COX-2 inhibition can be an attractive target for HNSCC, especially for combination use with chemotherapy.

Despite the multiple promising results of COX-2 inhibition in vivo and in vitro, clinical trials have failed to prove an absolute positive effect of celecoxib. A meta-analysis including malignancies such as lung cancers, prostate cancers, breast cancers, ovarian cancers, and colorectal cancers, concluded that the addition of celecoxib increased the overall response rate in non-small-cell lung cancer (NSCLC), but had no effect on other malignancies (38). However, a phase III randomized trial of advanced NSCLC showed no benefit of celecoxib on survival (39). As for head and neck carcinomas, a phase 2-3 study for advanced nasopharyngeal carcinoma showed improvement in 2-year local control but none in survival with the addition of low-dose celecoxib to chemotherapy (40).

These inconsistent results and the fact that COX-2 expression in tumor or stromal cells has no impact on the effect of celecoxib $(39,41)$ may be explained by the various expression patterns of the downstream PGE2 receptors, which vary between organs and cell lines (42). Multiple HNSCC cell lines have been reported with wide variation of EP expression patterns $(14,43)$. In our study, the mRNA expression level of EP1-4 genes varied between the two cell lines (Fig. 4). EP1 was absent in both cell lines, and FaDu showed a lower expression in the other receptors (EP2, 3, and 4) than Detroit 562, which may be the reason for the different response to celecoxib and the EP2 inhibitor.

The four types of PGE2 receptors, EP1-4, induce various signals, and each play different roles in malignancy $(42,44)$. The expression patterns, therefore, can affect the molecular functions of COX-2 inhibitors. EP1 shows a tumor-promoting role by activating pathways related to cell migration and invasion in various organs $(45,46)$, but may have an anti-tumoral effect in breast cancer (47). The role of EP3 in malignancy is unclear but seems to promote cancers $(48)$ including HNSCCs $(14,43)$. EP2 and EP4 receptors have similar responses, and are both linked to Gs proteins and activating adenylate cyclase, leading to increased cAMP levels. EP2 receptors induce angiogenesis (49) and suppress anti-tumor immune response (50). We have also previously reported that activation of EP2 receptors can promote EMT in HNSCCs (18).

Based on our present study, EP2 pathway activation may be related with cancer stemness, and targeting it can be useful in effectively improving chemo-sensitivity to DTX. Although EP2 inhibition improved chemo-sensitivity and downregulated cancer stemness-related genes, we could not show suppression in the sphere formation assay as celecoxib did. This may be explained by the relatively short half-life time of PF-04418948 compared to celecoxib (51). 
Furthermore, we have performed same assays using an EP4 antagonist, and could not determine any positive effect concerning control of cancer stemness (data not shown). As celecoxib inhibits all PGE2 receptors, combination blocking of specific receptors (such as simultaneous inhibition of EP2 and EP4) may be effective and needs to be further elucidated. Although celecoxib failed to show an absolute positive effect in clinical trials and long-term use of COX-2 inhibitors can lead to elevated cardiovascular risk (52), further detailed analysis of PGE2 receptor expression and downstream signaling may provide a possible therapeutic target.

There are limitations to our study. First of all, the clinical sample size was relatively small. This was due to the limited number of hypopharyngeal carcinoma patients who received surgery after induction chemotherapy. Second, the alteration of cancer stemness related genes were analyzed by PCR, and whether proteins of stemness markers were affected, needs further analysis. Last, although we were able to show that COX-2 inhibition improves chemosensitivity, and that COX-2 inhibition leads to suppression of cancer stemness, the precise mechanism underlying these two phenomenon needs further investigation. Whether COX-2 inhibition removed chemoresistance by directly blocking cancer stemness or by a different pathway remains unknown.

In conclusion, COX-2 inhibition can improve chemo-resistance to DTX in hypopharyngeal carcinomas through the inhibition of cancer stemness. Downstream PGE2 receptor expression seems to be a key factor to assess the effect of celecoxib and further study is awaited.

\section{Acknowledgements}

The authors would like to thank Dr Shintarou Nakamura and Dr Makoto Hosoya of Keio University School of Medicine (Tokyo, Japan) for technical assistance. The abstract was presented at the 2018 Annual Meeting of the American Association for Cancer Research April 14-18 in Chicago (IL, USA) and published as abstract no. 914 in Cancer Res 2018;78 (13 Suppl).

\section{Funding}

The present study was funded by a grant from the Japan Society for the Promotion of Science KAKENHI Grant-in-Aid for Young Scientists (grant no. 16K20275).

\section{Availability of data and materials}

The datasets used and/or analyzed during the current study are available from the corresponding author on reasonable request.

\section{Authors' contributions}

SS collected all the data, conducted data interpretation and analysis, and wrote the manuscript. MS, YW, FI, YuI and NN were involved in the acquisition and analysis of the data. KK was the pathologist who evaluated the pathological effect of chemotherapy. HO designed the study and performed proof reading of the article. YoI and $\mathrm{KO}$ were involved in designing the experiments and troubleshooting. SS and HO confirmed the authenticity of all the raw data. All authors read and approved the final manuscript.

\section{Ethics approval and consent to participate}

The protocols for the use of the clinical materials were approved by the Institutional Ethics Review Board of the Ethics Committee of Keio University School of Medicine (reference nos. 2010-013 and 2010-013-2). Informed consent was obtained in the form of opt-out on the website and by information in the hospital. All procedures for clinical tissues were performed in accordance with the principles of the 1964 Helsinki Declaration and its later amendments.

\section{Patient consent for publication}

Not applicable.

\section{Competing interests}

The authors declare that they have no competing interests.

\section{References}

1. American Cancer Society: Cancer Facts and Figures 2020. American Cancer Society, Atlanta, GA, 2020.

2. Visini M, Giger R, Shelan M, Elicin O and Anschuetz L: Predicting factors for oncological and functional outcome in hypopharyngeal cancer. Laryngoscope 131: E1543-E1549, 2021.

3. Hall SF, Groome PA, Irish J and O'Sullivan B: The natural history of patients with squamous cell carcinoma of the hypopharynx. Laryngoscope 118: 1362-1371, 2008.

4. Prince ME and Ailles LE: Cancer stem cells in head and neck squamous cell cancer. J Clin Oncol 26: 2871-2875, 2008.

5. Visvader JE and Lindeman GJ: Cancer stem cells in solid tumours: Accumulating evidence and unresolved questions. Nat Rev Cancer 8: 755-768, 2008.

6. Clara JA, Monge C, Yang Y and Takebe N: Targeting signalling pathways and the immune microenvironment of cancer stem cells-a clinical update. Nat Rev Clin Oncol 17: 204-232, 2020.

7. Chan G, Boyle JO, Yang EK, Zhang F, Sacks PG, Shah JP, Edelstein D, Soslow RA, Koki AT, Woerner BM, et al: Cyclooxygenase-2 expression is up-regulated in squamous cell carcinoma of the head and neck. Cancer Res 59: 991-994, 1999.

8. Camacho M, Leon X, Fernandez-Figueras MT, Quer M and Vila L: Prostaglandin E(2) pathway in head and neck squamous cell carcinoma. Head Neck 30: 1175-1181, 2008.

9. Mendes RA, Carvalho JF and Waal Iv: An overview on the expression of cyclooxygenase- 2 in tumors of the head and neck. Oral Oncol 45: e124-e128, 2009.

10. Gallo O, Masini E, Bianchi B, Bruschini L, Paglierani M and Franchi A: Prognostic significance of cyclooxygenase-2 pathway and angiogenesis in head and neck squamous cell carcinoma. Hum Pathol 33: 708-714, 2002.

11. Itoh S, Matsui K, Furuta I and Takano Y: Immunohistochemical study on overexpression of cyclooxygenase-2 in squamous cell carcinoma of the oral cavity: Its importance as a prognostic predictor. Oral Oncol 39: 829-835, 2003.

12. Saba NF, Choi M, Muller S, Shin HJ, Tighiouart M, Papadimitrakopoulou VA, El-Naggar AK, Khuri FR, Chen ZG and Shin DM: Role of cyclooxygenase-2 in tumor progression and survival of head and neck squamous cell carcinoma. Cancer Prev Res (Phila) 2: 823-829, 2009.

13. Yang CC, Tu HF, Wu CH, Chang HC, Chiang WF, Shih NC, Lee YS, Kao SY and Chang KW: Up-regulation of HB-EGF by the COX-2/PGE2 signaling associates with the cisplatin resistance and tumor recurrence of advanced HNSCC. Oral Oncol 56: 54-61, 2016. 
14. Abrahao AC, Castilho RM, Squarize $\mathrm{CH}$, Molinolo AA, dos Santos-Pinto D Jr and Gutkind JS: A role for COX2-derived PGE2 and PGE2-receptor subtypes in head and neck squamous carcinoma cell proliferation. Oral Oncol 46: 880-887, 2010.

15. Yang B, Jia L, Guo Q, Ren H, Hu Y and Xie T: Clinicopathological and prognostic significance of cyclooxygenase-2 expression in head and neck cancer: A meta-analysis. Oncotarget 7: 47265-47277, 2016

16. Sekimizu M, Ozawa H, Saito S, Ikari Y, Nakahara N, Nakamura S, Yoshihama K,ItoF, Watanabe Y,Imanishi Y,etal: Cyclo-oxygenase-2 expression is associated with lymph node metastasis in oropharyngeal squamous cell carcinoma under the new TNM classification. Anticancer Res 39: 5623-5630, 2019.

17. Fujii R, Imanishi Y, Shibata K, Sakai N, Sakamoto K, Shigetomi S, Habu N, Otsuka K, Sato Y, Watanabe Y, et al: Restoration of E-cadherin expression by selective Cox-2 inhibition and the clinical relevance of the epithelial-to-mesenchymal transition in head and neck squamous cell carcinoma. J Exp Clin Cancer Res 33: 40, 2014

18. Watanabe Y, Imanishi Y, Ozawa H, Sakamoto K, Fujii R, Shigetomi S, Habu N, Otsuka K, Sato Y, Sekimizu M, et al: Selective EP2 and Cox-2 inhibition suppresses cell migration by reversing epithelial-to-mesenchymal transition and Cox-2 overexpression and E-cadherin downregulation are implicated in neck metastasis of hypopharyngeal cancer. Am J Transl Res 12: 1096-1113, 2020.

19. Shi C, Guan Y, Zeng L, Liu G, Zhu Y, Xu H, Lu Y, Liu J, Guo J, Feng X, et al: High COX-2 expression contributes to a poor prognosis through the inhibition of chemotherapy-induced senescence in nasopharyngeal carcinoma. Int J Oncol 53: 1138-1148, 2018.

20. Saikawa Y, Sugiura T, Toriumi F, Kubota T, Suganuma K, Isshiki S, Otani Y, Kumai K and Kitajima M: Cyclooxygenase-2 gene induction causes CDDP resistance in colon cancer cell line, HCT-15. Anticancer Res 24 (5A): 2723-2728, 2004.

21. Patel VA, Dunn MJ and Sorokin A: Regulation of MDR-1 (P-glycoprotein) by cyclooxygenase-2. J Biol Chem 277: 38915-38920, 2002

22. Raju U, Ariga H, Dittmann K, Nakata E, Ang KK and Milas L: Inhibition of DNA repair as a mechanism of enhanced radioresponse of head and neck carcinoma cells by a selective cyclooxygenase-2 inhibitor, celecoxib. Int J Radiat Oncol Biol Phys 63: 520-528, 2005.

23. Wu M, Guan J,LiC, Gunter S, Nusrat L, Ng S, Dhand K, Morshead C, Kim A and Das S: Aberrantly activated Cox-2 and Wnt signaling interact to maintain cancer stem cells in glioblastoma. Oncotarget 8 : 82217-82230, 2017.

24. Deng Y, Su Q, Mo J, Fu X, Zhang Y and Lin EH: Celecoxib downregulates CD133 expression through inhibition of the Wnt signaling pathway in colon cancer cells. Cancer Invest 31: 97-102, 2013

25. Huang C, Chen Y, Liu H, Yang J, Song X, Zhao J, He N, Zhou CJ, Wang Y, Huang $\mathrm{C}$ and Dong Q: Celecoxib targets breast cancer stem cells by inhibiting the synthesis of prostaglandin $\mathrm{E}_{2}$ and down-regulating the Wnt pathway activity. Oncotarget 8: 115254-115269, 2017.

26. Liu Q, Yuan W, Tong D, Liu G, Lan W, Zhang D, Xiao H, Zhang Y, Huang Z, Yang J, et al: Metformin represses bladder cancer progression by inhibiting stem cell repopulation via COX2/PGE2/STAT3 axis. Oncotarget 7: 28235-28246, 2016.

27. Akutsu Y, Hanari N, Yusup G, Komatsu-Akimoto A, Ikeda N, Mori M, Yoneyama Y,Endo S, Miyazawa Y and Matsubara H: COX2 expression predicts resistance to chemoradiotherapy in esophageal squamous cell carcinoma. Ann Surg Oncol 18: 2946-2951, 2011

28. Shaik MS, Chatterjee A, Jackson T and Singh M: Enhancement of antitumor activity of docetaxel by celecoxib in lung tumors. Int J Cancer 118: 396-404, 2006.

29. Janakiraman H, House RP, Talwar S, Courtney SM, Hazard ES Hardiman G, Mehrotra S, Howe PH, Gangaraju V and Palanisamy V: Repression of caspase-3 and RNA-binding protein HuR cleavage by cyclooxygenase-2 promotes drug resistance in oral squamous cel carcinoma. Oncogene 36: 3137-3148, 2017.

30. Choe MS, Chen Z, Klass CM, Zhang X and Shin DM: Enhancement of docetaxel-induced cytotoxicity by blocking epidermal growth factor receptor and cyclooxygenase-2 pathways in squamous cell carcinoma of the head and neck. Clin Cancer Res 13: 3015-3023, 2007.

31. Chen KH, Hsu CC, Song WS, Huang CS, Tsai CC, Kuo CD, Hsu HS, Tsai TH, Tsai CY, Woung LC, et al: Celecoxib enhances radiosensitivity in medulloblastoma-derived CD133-positive cells Childs Nerv Syst 26: 1605-1612, 2010.

32. Zheng HC: The molecular mechanisms of chemoresistance in cancers. Oncotarget 8: 59950-59964, 2017.

33. Tong D, Liu Q, Wang LA, Xie Q, Pang J, Huang Y, Wang L, Liu G, Zhang D, Lan W and Jiang J: The roles of the COX2/PGE2/EP axis in therapeutic resistance. Cancer Metastasis Rev 37: 355-368, 2018.

34. Vinogradov $S$ and Wei X: Cancer stem cells and drug resistance: The potential of nanomedicine. Nanomedicine (Lond) 7: 597-615, 2012.
35. Huang Q, Li F, Liu X, Li W, Shi W, Liu FF, O'Sullivan B, He Z, Peng Y, Tan AC, et al: Caspase 3-mediated stimulation of tumor cell repopulation during cancer radiotherapy. Nat Med 17: 860-866, 2011

36. Majumder M, Xin X, Liu L, Tutunea-Fatan E, Rodriguez-Torres M, Vincent K, Postovit LM, Hess D and Lala PK: COX-2 induces breast cancer stem cells via EP4/PI3K/AKT/NOTCH/WNT axis. Stem Cells 34: 2290-2305, 2016

37. Guo Z, Jiang JH, Zhang J, Yang HJ, Yang FQ, Qi YP, Zhong YP, Su J, Yang RR, Li LQ and Xiang BD: COX-2 promotes migration and invasion by the side population of cancer stem cell-like hepatocellular carcinoma cells. Medicine (Baltimore) 94: e1806, 2015.

38. Chen J, Shen P, Zhang XC, Zhao MD, Zhang XG and Yang L: Efficacy and safety profile of celecoxib for treating advanced cancers: A meta-analysis of 11 randomized clinical trials. Clin Ther 36: 1253-1263, 2014.

39. Edelman MJ, Wang X, Hodgson L, Cheney RT, Baggstrom MQ, Thomas SP, Gajra A, Bertino E, Reckamp KL, Molina J, et al: Phase III randomized, placebo-controlled, double-blind trial of celecoxib in addition to standard chemotherapy for advanced non-small-cell lung cancer with cyclooxygenase-2 overexpression: CALGB 30801 (Alliance). J Clin Oncol 35: 2184-2192, 2017

40. Mohammadianpanah M, Razmjou-Ghalaei S, Shafizad A, Ashouri-Taziani Y,Khademi B,Ahmadloo N, Ansari M,Omidvari S, Mosalaei A, Mosleh-Shirazi MA: Efficacy and safety of concurrent chemoradiation with weekly cisplatin +/- low-dose celecoxib in locally advanced undifferentiated nasopharyngeal carcinoma: A phase II-III clinical trial. J Cancer Res Ther 7: 442-447, 2011.

41. Gulyas M, Mattsson JSM,Lindgren A,Ek L, Lamberg Lundström K, Behndig A, Holmberg E, Micke P and Bergman B; Swedish Lung Cancer Study Group: COX-2 expression and effects of celecoxib in addition to standard chemotherapy in advanced non-small cell lung cancer. Acta Oncol 57: 244-250, 2018.

42. O'Callaghan G and Houston A: Prostaglandin E2 and the EP receptors in malignancy: Possible therapeutic targets? Br J Pharmacol 172: 5239-5250, 2015.

43. Hoshikawa H, Goto R, Mori T, Mitani T and Mori N: Expression of prostaglandin E2 receptors in oral squamous cell carcinomas and growth inhibitory effects of an EP3 selective antagonist, ONO-AE3-240. Int J Oncol 34: 847-852, 2009.

44. Markovic T, Jakopin Z, Dolenc MS and Mlinaric-Rascan I: Structural features of subtype-selective EP receptor modulators. Drug Discov Today 22: 57-71, 2017.

45. Bai X, Wang J, Zhang L, Ma J, Zhang H, Xia S, Zhang M, Ma X, Guo Y, Rong R, et al: Prostaglandin $\mathrm{E}_{2}$ receptor EP1-mediated phosphorylation of focal adhesion kinase enhances cell adhesion and migration in hepatocellular carcinoma cells. Int J Oncol 42: 1833-1841, 2013.

46. Pan J, Yang Q, Shao J, Zhang L, Ma J, Wang Y, Jiang BH, Leng J and Bai X: Cyclooxygenase-2 induced $\beta 1$-integrin expression in NSCLC and promoted cell invasion via the EP1/MAPK/E2F-1/FoxC2 signal pathway. Sci Rep 6: 33823, 2016.

47. Ma X, Kundu N, Ioffe OB, Goloubeva O, Konger R, Baquet C, Gimotty P, Reader J and Fulton AM: Prostaglandin E receptor EP1 suppresses breast cancer metastasis and is linked to survival differences and cancer disparities. Mol Cancer Res 8: 1310-1318, 2010.

48. Amano H, Hayashi I, Endo H, Kitasato H, Yamashina S, Maruyama T, Kobayashi M, Satoh K, Narita M, Sugimoto Y, et al: Host prostaglandin E(2)-EP3 signaling regulates tumor-associated angiogenesis and tumor growth. J Exp Med 197: 221-232, 2003.

49. Pan MR, Hou MF, Chang HC and Hung WC: Cyclooxygenase-2 up-regulates CCR7 via EP2/EP4 receptor signaling pathways to enhance lymphatic invasion of breast cancer cells. J Biol Chem 283 11155-11163, 2008.

50. Obermajer N and Kalinski P: Key role of the positive feedback between PGE(2) and COX2 in the biology of myeloid-derived suppressor cells. Oncoimmunology 1: 762-764, 2012

51. af Forselles KJ, Root J, Clarke T, Davey D, Aughton K, Dack K and Pullen N: In vitro and in vivo characterization of PF-04418948, a novel, potent and selective prostaglandin $\mathrm{EP}_{2}$ receptor antagonist. $\mathrm{Br}$ J Pharmacol 164: 1847-1856, 2011.

52. Solomon SD, McMurray JJ, Pfeffer MA, Wittes J, Fowler R, Finn P, Anderson WF, Zauber A, Hawk E and Bertagnolli M; Adenoma Prevention with Celecoxib (APC) Study Investigators: Cardiovascular risk associated with celecoxib in a clinical trial for colorectal adenoma prevention. N Engl J Med 352: 1071-1080, 2005.

This work is licensed under a Creative Commons Attribution-NonCommercial-NoDerivatives 4.0 International (CC BY-NC-ND 4.0) License. 